\title{
High Altitude Climbing, High Reliability, COVID-19, and the Power of Observation
}

Daved van Stralen, MD, FAAP, Thomas A. Mercer, RAdm, USN

\begin{abstract}
Abstact:
Attempts to climb Mount Everest failed for thirty years until a mountain climbing physiologist joined the efforts. This story demonstrates the value of context, inductive processes, and pragmatism to generate local knowledge and solutions in austere, hazardous environments. In these environments, imperfect information and inaccurate models can kill. This story, viewed from the climbers' experience rather than scientists or leaders, underscores the vitality of engaged individuals overcoming physical, social, and mental adversity to "gain altitude." At the individual level, what high altitude climbers learned can support the neonatologist's efforts for the neonate to "gain life."
\end{abstract}

Three times men had climbed to more than 28,000 feet, unaided by oxygen apparatus, and failed to reach the summit. Eric Shipton (1952) (1)

\section{"In 1953, Sir Edmund Hillary and Tenzing Norgay achieved Mount Everest's summit, at 29,032 feet, the highest point on Earth. Not only did this feat change high altitude climbing practices, but it also led to advances in science that culminated in two scientific and medical expeditions: the Himalayan Scientific and Mountaineering Expedition of 1960-61 (2) (the "Silver Hut" Expedition from the wood hut painted in silver (3)) and the American Medical Research Expedition to Mount Everest 1981 (4). "}

Introduction:

In 1953, Sir Edmund Hillary and Tenzing Norgay achieved Mount Everest's summit, at 29,032 feet, the highest point on Earth. Not only did this feat change high altitude climbing practices, but it also led to advances in science that culminated in two scientific and medical expeditions: the Himalayan Scientific and Mountaineering Expedition of 1960-61 (2) (the "Silver Hut" Expedition from the wood hut painted in silver (3)) and the American Medical Research Expedition to Mount Everest 1981 (4). Thirty-five years after Hillary and Norgay's success, adventure travel was beginning to bring to the summit those without mountaineering experience, culminating in the highly publicized 1996 Mount Everest disaster when eight climbers died in a single blizzard $(5,6)$.

During the previous 30 years, from 1921-52, mountain climbers from eleven expeditions to Everest failed to climb higher than about 27,000 feet (7-11). The highest altitude climbers had reached was 1,000 feet from the peak: an altitude that seemed the limit of human endurance with climbers.

George Mallory: Lassitude is common, [what] was unduly exhausting [was]... anything that might be considered abnormal, such as cutting steps, [d]iminution of desire to reach the summit (12).

Bill Tilman: Lethargy and loss of judgment...becoming callous and fatalistic. A climber on the upper part of Everest is like a sick man climbing in a dream (8).

In 1953, climbers from the British Mount Everest expedition reached the summit.

My initial feelings were of relief-relief that there were no more steps to cut-no more ridges to traverse, and no more humps to tantalize us with hopes of success. I looked at Tenzing..., there was no disguising his infectious grin of pure delight...It was 11:30 a.m...l turned off the oxygen and removed my set...I now produced [the camera] and got Tenzing to pose on top for me, waving his ax on which was a string of flags - British, Nepalese, United Nations, and Indian.

Sir Edmund Hillary (13)

The year before the successful climb, the British Joint Himalayan Committee had sent a 1952 British preparatory expedition to Cho Oyu, a 26,800-foot mountain lying 20 miles west of Everest. Included in the climbing team was a physiologist who was also an experienced climber. The expedition leader had suggested that the expedition "carry out experiments in the use of oxygen apparatus; to study physiological problems of high altitude climbing, such as acclimatization and deterioration, diet and liquid consumption; and to test clothing and equipment" (14).

One year after the physiologist, Gifford Pugh, joined the effort, Sir Edmund Hillary and Tenzing Norgay reached Everest's summit, smiled, removed their oxygen set, and took photos. From Eric Shipton's list of studies (above) (14), we know high altitude climb-

NEONATOLOGY TODAY is interested in publishing manuscripts from Neonatologists, Fellows, NNPs and those involved in caring for neonates on case studies, research results, hospital news, meeting announcements, and other pertinent topics.

Please submit your manuscript to: LomaLindaPublishingCompany@gmail.com 
ers were cognizant of the problems impeding success and were familiar with human performance science in low oxygen environments.

\section{"There is an allure in taking this story as a battle over oxygen at high altitude or comparing hypoxic lung function between high altitude mountain climbers and the premature neonate."}

There is an allure in taking this story as a battle over oxygen at high altitude or comparing hypoxic lung function between high altitude mountain climbers and the premature neonate. Such constrained, decontextualized views generally come from an authority group and limit one's perspective. When they become the dominant view, they limit meaning and interpretation. Instead, we use the Everest climbers' story to demonstrate observation and engagement as domains of expertise to achieve high reliability. Everest climbers' expertise produced articulate, accurate observations of the problems they encountered and characterized the need for better science $(7,8,12,15)$. Scientists' expertise produced a better understanding of environmental hypoxia and engineered technology for oxygen administration that could be readily adapted from military aviation (16-18).

This is not about querying climbers for their needs, teaching science to climbers, or teaching climbing to scientists. If that were the case, the parties involved would have solved the problem far sooner. Nevertheless, just as a gap exists between theory and practice (19) or discrete concepts and continuous perception (20), a discontinuity, a separation, exists between the protected, wellcontrolled laboratory study and the dangerous, volatile high altitude environment.

This is a story of engaging multiple problems embedded in a variety of domains within an unforgiving environment. Knowledge must be in hand rather than called upon when needed. It is in this sense that we draw together high altitude climbing and neonatology. "Predicting what would happen to the first human beings to climb that high [27,000 feet] was therefore literally a matter of life or death - here, inaccurate models could kill" (18). We can say the same for the smallest premature baby; inaccurate models could kill.

\section{High Altitude Climbing and Neonatology as Liminal Spaces}

One crosses a vague threshold when entering the high-altitude environment. As for any extreme environment or experience, you cannot quite tell when things are about to change or have changed. The familiar structured environment with recognizable internal logic is lost. The individual rapidly transitions to an unstructured environment with unrecognized internal logics that disorient, confuse the senses, create isolation, and maybe existential fear. Perception and sensemaking also transition as familiar objects gain additional meanings that create ambiguity and paradox. Affective judgment becomes more critical to sensitize one for detecting subtle or nuanced threats and hazards and the salience of early heralds of failure. A new identity is gained with acceptance into a new community (21). Without losing our sense of proportion, the mind works similarly whether you enter the liminal space on your first day on the job, your first resuscitation as an intensive care nurse, fellow, or attending as well as during a live-or-die situation (personal communications from colleagues and experiences of the authors).

This threshold marks liminality (liminal = threshold), an anthropology term referring to the crossing of a threshold in life. In anthropology, "liminal" refers to rites that signify status changes, such as from childhood to adulthood. COVID-19 has formed an expanded liminal space where the threat of COVID-19 has a more significant effect on operations and society from maladaptive stress responses and fear reactions than through death alone. COVID-19 has generated an ecology of fear (22). Before COVID-19, the NICU safely sheltered babies; now, the NICU space itself may bring harm. High altitude and the NICU are liminal spaces.

\section{"This threshold marks liminality (liminal = threshold), an anthropology term referring to the crossing of a threshold in life. In anthropology, "liminal" refers to rites that signify status changes, such as from childhood to adulthood."}

Inaccurate, possibly deadly models created with missing knowledge or lack of experience at altitude interfered with acceptance of the use of oxygen apparatus by climbers. Similarly, inaccurate models for COVID-19, despite constant refinement and improvement, interfere with prevention and management acceptance. In these situations, observation is all we have.

However, observation within the liminal space may be for familiarity and homeostasis security or for the discordant event to identify threats and support safety. Mountaineering and HRO make a big deal about the difference between the familiar and the novel. Our brains rapidly identify patterns fundamental for intelligence, language, imagination, invention (23). Through pattern recognition and engagement, we use the familiar to learn by doing (24). A person may find or fit rules and concepts into the observed patterns, gaining a false sense of security $(22,24)$. Our brains rapidly identify threats through the amygdala, triggering reflexive vigilance and action (25). When neuromodulated, the elicited stress-fear-threat cascade's adaptive functions drive effective action while maladaptive responses create significant damage (26).

Perceptions also divide between cortical hemispheres, differentiating the novel (right hemisphere) from the familiar (left hemisphere) unrelated to handedness. With age, the functions meld to produce wisdom.

The right hemisphere identifies novelty for rapid, diffuse responses to the unexpected and to support avoidance. It can maintain high levels of arousal, supporting the negative, intense effect necessary for high-risk engagement. Assessing multiple objects and their context, noticing small differences between stimuli, and parallel processing all support global analysis in the liminal space (27). 
Right hemisphere behaviors include predator responses (27) and social interactions (28) that drive avoidance, fear responses, predator escape, and aggressive responses (27). There is also a bias toward social interactions and attendant bonding and affiliation, including facial recognition and reading facial expressions, gaze directions, and intonation (28).

\section{"Familiarity is how an organism approaches food and conspecific social interactions. Social emotions, awareness of other beings, and a generally positive affect drive social connection (28)."}

The left hemisphere identifies the familiar and is more developed for cognition. Familiarity is how an organism approaches food and conspecific social interactions. Social emotions, awareness of other beings, and a generally positive affect drive social connection (28). Focused attention supports considered responses to decide between alternatives and generate sequential actions (27).

Our brain and behaviors have prepared us to function in the liminal space if we can maintain neuromodulation (29). People may not recognize when they enter a liminal space since some spaces are contingently liminal. For example, a routine winter climb changes to a liminal space as a storm arrives or parental visitation of their baby, interrupted by abrupt pulmonary hypertension, becomes a liminal space. The problem is not the abrupt change as much as long episodes of routine operations that generate complacency in the team and expectations from the sojourner. We risk losing acknowledgment of the subtle routines that are necessary to maintain high reliability. For example, in high altitude climbing, the abrupt decrease in air pressure from an unexpected storm, the equivalent to a rapid increase in altitude, disrupted a group of adventure teams on Everest in 1996. Eight climbers died.

\section{Liminal Spaces and Inductive Processes}

The liminal space environment would create the ecology of fear (22) but for the absence of a threat recognizable by the sojourner. Consequently, sojourners may operate oblivious to dangers, interfere with operations, or, more seriously, use their expectations to drive operations. The rarity of a severe life threat can be hard to explain to outsiders, as we see with the social and political acceptance of the COVID-19 threat. On Everest in 1996, some sojourners expected to reach the summit, an accomplishment they had purchased, and some leaders had created a mystique of omniscience, an eminent capability that created passive fellow guides. Such leader myth-making stifles communication of disconfirming information and stifles concerns about ascending during a storm (5).

The environment is the enemy in a liminal space. Organizations operating in the liminal space that rely on strong leaders, of whatever style or philosophy, run the danger of failure from abrupt changes $(5,30,31)$. The liminal space is not an environment where monitoring, sensemaking, or attention can help us. When the problem is embedded in a hostile environment, observation and engagement are the functions we rely upon as we explicate. In the liminal space, constant observation and reciprocal feedback, generating and testing information, all rely on inductive processes.

Leonhard Euler (32) describes the problem this creates:

We can place our highest hopes in observations; they will lead us continually to new properties, which we shall endeavor to prove afterward. The kind of knowledge which is supported only by observations and is not yet proved must be carefully distinguished from the truth; it is gained by induction as we usually say...Indeed, we should use such a discovery as an opportunity to investigate more than exactly the properties discovered and to prove or disprove them; in both cases, we may learn something useful.

George Pólya (32) described observation as "an accurate watching and noting of phenomena as they occur in nature with regard to cause and effect or mutual relations." But observation can identify facts that do not align with our minds and knowledge, for example, when climbers considered the use of oxygen at high altitudes, discussed below. We adapt our minds to newly observed facts by using inductive processes. That is, we should revise our beliefs if our observations generate a compelling reason to change (32). The experiences of high altitude climbers created observed facts that challenged knowledge. Neonatology is no different. Like high altitude climbing, neonatology relies heavily on observation and inductive processes to adapt to newly emerging facts.

\section{"Neonatology is no different. Like high altitude climbing, neonatology relies heavily on observation and inductive processes to adapt to newly emerging facts."}

We have only observation to adapt our knowledge to emerging facts. This observation drives inquiry, described by John Dewey as "always a behavioral response of a reflective organism to its environing conditions....inquiry belongs to 'action or behavior,' which takes place in the world, not just within the mind or within consciousness...Inquiry... is what Dewey termed an 'outdoor fact'" (33).

In the disorientation of the liminal space, knowledge, and facts suffer. To engage the liminal space, we reduce complexity by actions guided by reciprocal feedback from the environment, a method also used by a special group in SOCOM (US Special Operations Command, personal communication). The individual can then immediately initiate inquiry while concomitantly reducing volatility and threats. The standard method of initially investigating or differentiating complexity, chaos, and uncertainty needlessly expends time, allowing it to worsen.

We build from perception to observation, which then drives inquiry and experience. From experience, we give meaning to our actions and the information we generate. Coincidently, this parallels the philosophy of pragmatism. In the liminal space, we do not have certainty, particularly for antecedent events, impairs our ability to 
act from what happened earlier. This experience also interferes with scientific logic and the Cartesian approach to reach truth (34) or bring about a resolution. Instead, we use the possible consequences of our actions to guide inquiry, likely the most difficult tenet of pragmatism to appreciate (34).

Perception, not recognition, generates observation. John Dewey diminishes recognition as the 'use of matter as a means.' Perception carries our past experience into the present to enrich its content, forming observations (35). Observation is then in service to an outcome, achieving 'practical consequences,' and not to a process (36). Observation as pragmatism moves us forward, whether to gain altitude on a mountain or gain life in the NICU.

\section{"Perception may seem dependent on definitions, but definitions come up short in the turmoil of the liminal space. Descriptions of how something is used, an action performed, or a situation experienced all carry meaning."}

Perception may seem dependent on definitions, but definitions come up short in the turmoil of the liminal space. Descriptions of how something is used, an action performed, or a situation experienced all carry meaning. Too quickly, labeling things becomes an unconscious act (35) with nothing learned when we analyze definitions (Charles Sanders Peirce in (36)). Instead, the conscious act of experience as a "cooperation of internal needs and external materials" converts 'cause and effect' into 'means and end,' transforming simple interactions into more complex participation (35). This conversion is an observation as cause and effect, used in the inductive processes described by Pólya (32).

The liminal space generates extreme experiences and identifies discrepancies between the individual's appraised meaning and more global meaning. Reappraisal integrates the events, causes, and implications of the experience, reducing existential stress (37). Inquiry as interaction and participation is to operate in the liminal space as a meaningful experience rather than sensations or "brain events" $(35,38)$. Life-threatening situations are unique, and the pragmatic leader induces a sense of shared experience, tying into the ideals of optimism, hope, and resilience $(30,39)$. Reappraisal, as a regulatory strategy, contributes to this resilience (40).

Pragmatism is to resolve disruption. Experience brings resolution. When we complete an experience, we give it meaning (41).

\section{The Problems of High Altitude}

When we view Everest's problem as low atmospheric oxygen pressure and climbers' intransigence to accept carrying the oxygen apparatus, we reduce the problem to the "use of oxygen." While bringing clarity to the failure of the British Mount Everest expeditions, it misleadingly creates distinctions between theoretical and practical challenges, sporting and scientific conduct, research and operations goals, and the influences of laboratory studies and field operations (18).

Such reductionist, de-contextual approaches move the discussion away from situations where nuanced local forces strongly influence action. Once out of the immediate environment, we can readily believe we would not have had such judgment. Discussion of Everest climbers allows for admiration of the climbers while modestly diminishing them for their resistance to oxygen. Evaluating decisions made by healthcare professionals and parents operating in a challenging environment comes under similar scrutiny. This differentiation is the practical distinction between the normative and pragmatic stances (24).

Instead, we will present the distinct problems described by the climbers with the science that was then available: acclimatization, oxygen, appetite and thirst, fatigue, and temper. Engagement of a situation focuses one's attention, decision-making, and efforts on subtle though critical elements. For example, retrograde intubation is a method to intubate the trachea by passing a guidewire percutaneously from the cricoid membrane then out the nose or mouth. Many review articles introduced this procedure to emergency medicine. One author (DvS) had initiated the development of a resuscitation manikin for this procedure (42), leading to a discussion with numerous emergency physicians. Several had attempted the technique, experiencing the endotracheal tube passing over the guidewire and consistently entering the esophagus. The review articles had omitted holding the guidewire taut while guiding the endotracheal tube, a maneuver vital for success (43). The high altitude climbers' observations and descriptions came from the intimate engagement of mundane yet life-threatening situations. Their concern was how to gain altitude. For various reasons, their concerns and the vital information they generated did not reach those who need it, or the information was lost.

At high altitude came "great exhaustion, from which it is not possible wholly to recover without a prolonged rest at a very much lower altitude" (10). Is that the most serious obstacle on Mount Everest? It depends on whether it is top-down from the expedition organizers and leaders or bottom-up from expedition climbers. It depends on whether it is from outside of the events, a fixed-point to assure progressive forward motion, or within, moving with the flux of events while striving to endure. Eric Shipton described it as a more serious obstacle than "the altitude, the severe cold, and the wind." The value placed on seriousness may differ between a spectator and an insider. The high-reliability theory makes a big deal of these differences. The series describing HRO for Neonatology Today is an effort for synthesis. When this is not synthesized, science and theory move in a different direction from practice and operations.

\section{Acclimatization}

Eric Shipton described climbing the last 4,000 feet to the top of Everest in a single day drained the climbers; they were too exhausted to continue. The British attempts to climb Mount Everest in 1922 and 1924 failed after the climbers "had gone too high too soon." In 1933 they again "under-rated the resources of our opponent" (1). Climbers knew they could gain altitude through acclimatization. For example, Charles Howard-Bury found he had more energy after six months living in Tibet, then applied that experience to climbing above 18,000 feet (15). They also found that slow acclimatization resulted in the capacity to eat more normal food (44), essential for maintaining vitality. 
Extended acclimatization, though, comes with costs and risks. Food and fuel necessary for prolonged stays must be transported, but climbers also found physical deterioration. While sufficient food was available, the lack of appetite during acclimatization caused decreased food intake, a possible cause of the rapid physical deterioration during acclimatization (10).

Acclimation helped Everest climbers reach. 27,000 feet, now they needed to find a way to climb higher. While the alpine climbing community had known that oxygen could augment or replace acclimatization, it was a visit to Oxford in 1921 regarding stoves that brought scientists closer to the climbing community $(17,18)$. Georges Dreyer's oxygen tests for aviation using a low-pressure chamber became a source of information for mountain climbers $(17,18)$. John Haldane had conducted studies of acclimatization on Pikes Peak in 1911 (16). The effects of acclimatization become apparent after 2-3 days. A more sensitive response to $\mathrm{CO}_{2}$ results in respiratory alkalosis and a subsequent increase in breathing. $\mathrm{CO}_{2}$ levels reached 2/3 normal levels after two weeks. Hemoglobin also increases over several weeks (16).

Fatigue is an early effect of acute hypoxemia when newly arrived in villages at 7,000 feet, an experience one author (DvS) uses to teach lung dynamics. Visitors to Mammoth Lakes, California, state the cause of their fatigue is lack of sleep, excitement, or too much I too little food. However, a few breaths of "pressure breathing," forced exhale against pursed lips, resolves the fatigue, demonstrating its pulmonary nature. This method also treats high altitude pulmonary edema at 20,000 feet (personal experience, DvS).

\section{"The effects of acclimatization become apparent after 2-3 days. A more sensitive response to $\mathrm{CO}_{2}$ results in respiratory alkalosis and a subsequent increase in breathing. $\mathrm{CO}_{2}$ levels reached 2/3 normal levels after two weeks."}

Scientists had predicted that acclimatization would be impossible above 20,000 feet (7). Experience seems to bear this out. At heights greater than 18,000 feet, a prolonged stay "permanently lowers the vitality" (15), with physical lethargy progressively more intense, leaving climbers gasping and panting at rest (10). The body "simultaneously loses both weight and strength" (12), and at about 21,000 feet, muscle wasting becomes consequential (10) and may offset the benefit of acclimatization (8). Nevertheless, Everest climbers did acclimatize at 21,000 feet and even higher (7). "Why [scientists made their prediction]...will always remain a mystery to me; but possibly they were misled by the fact that so many climbing expeditions in the past failed somewhere in the region of 23,000 feet above sea-level," Charles Granville Bruce (7). Everest climbers searched for the balance between acclimatization and deterioration $(10,12)$.

We could too readily discount the acclimatization controversy as a product of armchair science at a distance from the mountains, the result of crude measurements and unrefined hypotheses, or we could reject experience as spurious or superstition. A review of the causes of Mount Everest deaths above 8,000 meters $(26,247$ feet) over 85 years questioned whether adequate acclimatization is possible at that altitude (45). Before rejecting the degree of the climbers' experience, we may better be served by understanding the practical reasons for such beliefs, the context of operations, and their interactions.

Eric Shipton described the amount of time spent in sleeping bags. When the sun disappeared around 4:00 p.m., it became too cold to sit outside. They commonly remained in their sleeping bags until 9:00 a.m. in good weather. Bad weather would keep them in their tents for much longer (10). Within seven days of bed rest during bed rest studies, the thigh muscle decreases by $3 \%$, small but significant. After 20 days, maximal torque decreases in the ankle $(9 \%)$ and knee (16\%) extensors, quadriceps muscle decreases by $10 \%$, and lower limb power, force, and velocity decrease by 19.8$43.6 \%$. By four weeks, fatigability increases, and exercise capacity decreases (46). This has no relation to the use of oxygen.

Without knowing the science, the Everest climbers reported the limitations and risks of acclimatization as a general physical deterioration and loss of muscle mass, similar to what is measured in bedrest studies. Elsewhere they describe increased fatigability with time in higher altitudes. This ability to use observation produced from engagement had initiated learning by doing and advanced climbing, albeit slowly. Responding to the impossibility of acclimatization above 20,000 feet, the climbers considered science as informational rather than dictatorial. They acted within local circumstances, typical of the pragmatic stance.

\section{"A science that does not accurately describe the situation or allow for variation risks irrelevance. This is less a property of science than the mistranslation of analysis, deductive processes, and reliance on deterministic inferences."}

A science that does not accurately describe the situation or allow for variation risks irrelevance. This is less a property of science than the mistranslation of analysis, deductive processes, and reliance on deterministic inferences. Climbers come from a pragmatic stance of synthesis, inductive processes, and affective inferences (24). While the use of science from a fixed-point frame of reference does not translate well to high altitude climbing, science from within the flux and flow of events and the consequent doubt and unpredictability does.

\section{Oxygen}

The use of oxygen as a means to gain altitude shifted to its use for some beneficial effect. The Everest climbers were familiar with the research on high altitude aviation and oxygen. Working in a chamber pressurized to 25,000 feet was helped by 1 liter per minute oxygen flow (47). Hugh Ruttledge (48) thought the use of oxygen might replace acclimatization and provide strength for difficult stretches to climb higher.

Oxygen was not a matter of particular importance to expedition leaders $(7,12)$, who believed it provided no effect for some climb- 
ers while it helped others (12). For those it helped, some thought the benefit was from inadequate acclimatization (12) or illness (8). George Mallory believed oxygen might have restorative value, thus leaving its use to one's personal opinion (7). Even with this skepticism, Mallory used oxygen, including his last climb to his death. When Bill Tilman used oxygen, he felt "sprightly" and climbed more easily to 25,000 feet but without increased speed (8). At 25,000 feet, for George Finch, oxygen made carrying a strenuous load feel a brief walk (7).

\section{"The belief developed that oxygen helped with exertion, and climbing became less difficult, but the climber could have reached higher altitudes without oxygen (7)."}

The belief developed that oxygen helped with exertion, and climbing became less difficult, but the climber could have reached higher altitudes without oxygen (7). Some of the difficulty came from the 35-pound weight of the oxygen apparatus, which counterbalanced any advantages $(7,8)$. However, around 23,000 feet, its restorative function brought some advantage though it still seemed possible to climb Everest without the oxygen (7). Some considered oxygen unethical or unsportsmanlike, but most of these discussions were in Britain and not commonly discussed on the mountain. Oxygen would be considered ethical if the lack of oxygen alone prevented reaching the summit (8).

Noel Odell described a peculiar benefit of acclimatization overuse of oxygen - the speed of descent unencumbered by the oxygen apparatus. In fairness to the use of oxygen, speed came from glissading, an indulgence the apparatus interfered with (12). One glissades by sliding down the snow on one's feet, supported by the ice axe, and an accepted descent method for Everest climbers.

These discussions of oxygen's benefits and drawbacks come from the normative stance, a fixed point way from engagement in the flux of events (24). This is similar to healthcare discussions of new therapies or new diseases such as COVID-19, discussions made at a distance from the patient and caregivers immediately involved with care.

"What would make the person right?" generates useful information for learning and improving programs. It moves our thinking into the flux of events; what is it that I do not see that would make them do it - unnoticed causations, missing information, corrupted communication, and other influences that are washed out when we evaluate from a distance.

Within the flux of events, decisions for using oxygen were based on the incomplete flow of information between scientist and climber, instability on a steep slope, the sense of suffocation from the mask, or sudden loss of oxygen flow, causing sudden unconsciousness.

The discontinuity between contextual practice and decontextualized theory from science that Pugh would later productively engage (19) is well-described by Tilman (8):
It is an engaging but fatal characteristic of scientists that once presented with a material problem of this kind [oxygen at high altitude]. They set about the solution with a single-minded devotion that excludes any other considerations whatsoever, be they ethical, humane, or merely of common sense.

Scientists had warned that climbers could probably not reach any great height without oxygen (7). They added the warning that to stop using oxygen probably would cause death (7), inadvertently creating a reason not to use oxygen: if climbers are at altitude without oxygen and become disconnected, they may suddenly collapse (Francis Younghusband (7)). In effect, not using oxygen appeared safer. One solution offered was protection from collapse by acclimatization at 21,000 feet or only use oxygen above 27,000 feet (12). Without close communication, climbers found practical solutions based on the environment with little involvement of science.

Yet, climbers made excursions to 24,000 feet and remained conscious without oxygen. For the climbers, this was evidence supporting the greater probability they could reach the summit without the oxygen apparatus's additional weight (Howard Somervell (7)). The use of aviation as a model did not apply to climbers; airmen may have value in the pressure chamber, and oxygen for them is essential, but in mountain climbing, they have survived without oxygen (15). The pragmatic stance of the climbers is apparent in Shipton's query: "No one has yet produced a satisfactory answer to the objections by actual demonstration, and the debate continues" (10).

\section{"This difference between scientists and climbers lies in the domains they learn - cognitive, affective, or psychomotor (49). Scientists tend to learn in the cognitive learning domain of facts, concepts, models, and theories. The cognitive domain more readily translates into objective measures for progress toward competence in the subject or discipline."}

This difference between scientists and climbers lies in the domains they learn - cognitive, affective, or psychomotor (49). Scientists tend to learn in the cognitive learning domain of facts, concepts, models, and theories. The cognitive domain more readily translates into objective measures for progress toward competence in the subject or discipline. The cognitive domain provides our common verbal knowledge, knowledge organization, and cognitive strategies. The affective learning domain (50), in contrast, focuses on "how this will help" and provides the context necessary to give meaning to information. This approach increases the motivation to learn and to understand better the knowledge that was gained. Motivation describes responsiveness to phenomena, valuing knowledge, and the worth of an object or idea. 
"I think the most obvious lesson to be learnt is that the only trials and experiments of any value at all are those carried out by mountaineers themselves at heights of over 23,000 feet." He also stated, "[S]cience and mountaineering should be kept distinct," Bill Tilman (8)

Some climbers would not wear the 35-pound oxygen apparatus because of the weight (15). Finch believed the advantages counterbalance the disadvantages of the weight, particularly above the foot of the North Col slopes because full recovery from fatigue is no longer possible at 23,000 feet (7). Weight requires energy to carry, but the climber conserves energy with rhythmic movement, balance, and precise placing of the feet (10). Weight shifting from the oxygen apparatus could cause instability on a steep slope ( 7 , $8,10)$.

\section{"Today, human factors studies would have helped the problem with face masks and the sense of suffocation (7, 8). Because oxygenation and sensation are independent entities, the climber may remove the mask to relieve the sense of suffocation yet not recognize hypoxemia."}

Today, human factors studies would have helped the problem with face masks and the sense of suffocation $(7,8)$. Because oxygenation and sensation are independent entities, the climber may remove the mask to relieve the sense of suffocation yet not recognize hypoxemia. One climber reported: "I noticed then that our faces were all a curious blue colour in the morning, due to what is called, I believe, cyanosis of the blood. I cannot say what the effect will be if oxygen is taken to aid the human effort." (15). Suffocation is arguably the most fearsome way to die.

The most serious threat from oxygen use, because it is beyond the climber's control, was the sudden loss of oxygen flow. The Mount Everest Committee was warned about this problem with oxygen - if oxygen ran out at 27,000 feet, the climber might immediately collapse (7). Finch, a physical chemist and oxygen proponent, warned that interrupted flow would cause sudden unconsciousness (7). Somervell (7) and Shipton (10) wrote of their concerns that oxygen might run out at attitude producing sudden collapse of the climber. Causes for interrupted flow include breakdown or accident with the apparatus $(7,10)$, problems with face mask, an oxygen supply that lasts only 8 hours $(7,10)$.

Information supporting sudden collapse came from aviation tests in pressure chambers $(10,17,18)$. Everest climbers were also familiar with several incidents of death from ballooning at 27,000 to 30,000 feet (51). In 1862 a meteorologist and his assistant reached 26,000 feet and had become paralyzed, unable to release the gas valve. The assistant finally reached the valve with his mouth, and they descended, but not after reaching 30,000 feet. The second incident in 1875 led to the deaths of two passengers, the scientist survived. That balloon also reached 30,000 feet.

They knew the stories, but the stories belonged to the scientists, not the climbers. The empirical experience of the climbers differed from the empirical studies of the scientists. Mount Everest climbers had acclimatized without oxygen, attained the same altitudes as the balloonists, and could still climb without oxygen (12). Somervell (7) described an accident with the oxygen apparatus. The climber did not become immediately unconscious; the apparatus was then disconnected and repaired. The scientists had warned they could not reach such heights without oxygen, but the climber had and stayed conscious despite the sudden loss of consciousness.

But it was the insidious nature of the "want of oxygen" (51) that remained:

Body and mind become feebler little by little, gradually and insensibly. There is no suffering. On the contrary, one feels an inward joy (16).

The subject does not recognize a loss of consciousness and hotly denies it. To convince the subject, the subject will write while the experiment is conducted (10).

From climbing:

The intelligence is gradually numbed as the oxygen supply diminishes, and the body comes nearer to exhaustion (7).

These descriptions of the "want of oxygen" gain richness from personal engagement and the climbers' pragmatic stance. The "want of oxygen" problem had become more accurate: fatigue embedding into a dangerous high altitude environment. This dilemma differs from a singular situation: the continual drive to act, the rhythmic forward movement step after step, exhaustion comes painlessly. Scientists with single-minded devotion worked to solve problems, then offered facts from their labs. The Everest climbers worked to gain altitude, a continuous process, while science worked to make models, a process with a conclusion.

The human body responds to the low partial pressure of oxygen with hyperventilation (16), which appears to defend alveolar $\mathrm{PO}_{2}$ at about $35 \mathrm{mmHg}$ (4). Alveolar $\mathrm{CO}_{2}$ levels decrease from 22 $\mathrm{mmHg}$ at 29,000 feet to $14 \mathrm{mmHg}$ at 25,700 feet (52). At 8,000 meters (about 26,000 feet), this hyperventilation level produces alveolar $\mathrm{PCO}_{2}$ of $8.0 \mathrm{mmHg}$ and arterial blood $\mathrm{pH}$ between 7.7 and 7.8 (4). The only gas measurements from an Everest expedition before 1950 were on the 1933 expedition. Measurements at 23,000 feet and a barometric pressure of $339 \mathrm{mmHg}$ showed an alveolar $\mathrm{CO}_{2}$ concentration of $19.3 \mathrm{mmHg}$ (53).

Notwithstanding medical professionals' belief that hypoxemia causes feelings of suffocation, descriptions by those who have experienced hypoxemia are of insidious onset related to decreasing awareness associated with comfort (including the authors' personal experience). This relationship is essential information when we discuss limitation or withdrawal of support when ethically indicated. Also, chronic hyperventilation with $\mathrm{CO}_{2}$ levels of 19.3 $\mathrm{mmHg}$ at 23,000 feet and $8.0 \mathrm{mmHg}$ at 26,000 feet lend support to the experience in long-term mechanical ventilation when the voluntary respiratory effort of patients creates respiratory alkalosis, though to a lesser degree, with an average $\mathrm{pH}$ of 7.46 and average $\mathrm{CO}_{2} 26 \mathrm{mmHg}$ (range 23.1-28.8) (54). These well-documented experiences in extreme environments inform our ability to provide compassionate care to our patients and families. 
Diet

Appetite is consistently decreased at high altitudes $(7,8,12,15)$. At 22,000 to 23,000 feet, after a week or so, hunger is absent. It is impossible to eat enough, even with tempting foods (8). This is consequential with loss of weight at altitude (8). Thirst is not felt above 24,000 feet (8).

\section{"Whether breast or bottle-fed, the infant will tire out and, despite feeding by breast or bottle, does not finish the feeding. Heart failure, inadequate oral intake, and increasing dehydration reach the degree that heart failure is buried in hypovolemia- dehydration."}

It may confound some that one can be dehydrated without thirst. When dehydration causes hypovolemia, the initial blood flow decrease is to the stomach, which causes an ileus and loss of appetite. Heart failure in infants also causes an ileus. Whether breast or bottle-fed, the infant will tire out and, despite feeding by breast or bottle, does not finish the feeding. Heart failure, inadequate oral intake, and increasing dehydration reach the degree that heart failure is buried in hypovolemia-dehydration. The mother reports her infant is feeding but, unless specifically asked, does not report her infant finished the feeding. The quickest way to demonstrate this is to look at the reverse; your thirst quenches before the water is absorbed.

\section{Fatigue and temper}

Climbers feel lazy. There is always needed effort to concentrate thoughts (15); lassitude is common, there is lack of determination (7); diminution of mental operations, will power, the strength of purpose, desire to reach the summit (12); and lethargy and loss of judgment, becoming callous and fatalistic (8). Full recovery from fatigue is no longer possible at 23,000 feet (7).

Intense cold and heat loss reduce available energy (15) and sapped their desire and ability to climb (8).

Climbers have peevishness and irritability at a level of 22,000 feet (7).

Poor sleep is common, which "lowers the vitality enormously" (15).

\section{Ethics and kindness}

Climbing in an austere, hostile environment, relying solely on each other for rescue, creates an accepted ethical bond. This bond, by necessity, exceeds the drive to gain altitude and reach the summit. "And of all the principles by which we hold the first is that of mutual help," George H. Leigh-Mallory (15). If any climber or porter was sick or abnormally exhausted, he must be escorted to a lower altitude at the first opportunity. It is taken for granted that such an evacuation may interfere with the expedition.

In all, it may be said that one factor beyond all others is required for success...The climbers must have above all things if they are to win through, good fortune, and the greatest good fortune of all mountaineers, some constant spirit of kindness in Mount Everest itself.

\section{George H. Leigh-Mallory}

In 1985, while approaching Kyajo Ri peak (20,295 feet), a French climbing team encountered a European climber and his Sherpa guide. One was delirious and the other unconscious. The French team could not move an unconscious body from an altitude near 19,000 feet, but they did have hydrocortisone, at the time a suspected treatment for altitude illnesses. They injected the medication in the thigh of the unconscious climber, who awoke well enough that the French team could evacuate both climbers to Thame in the Solu Khumbu District. That is where they approached one of the authors (DvS) for permission to climb the author's permitted mountain, Mount Pharchomo (20,581ft). At the time, a permit restricted access for a four-day period when only the permitted climbers could be on the mountain. They presented their plight as a matter of fact situation as if they had encountered someone limping, despite the missed climb, delays, and costs. The ethics of high altitude climbing is one of kindness in the Himal.

(When in the US and recounting the story of the hydrocortisone, American physicians quickly pointed out to the author that no research supported the use of hydrocortisone for high altitude illness, especially high altitude cerebral edema.)

It is a testament to the attitudes necessary for climbing and the climbers' drive to continue pressing their accomplishments despite the mental and psychological strain. Engagement as pragmatism and inductive processes, also found in military and public safety operations, undoubtedly contributed to their high-stress capacity and performance.

The Everest climbers placed their hopes in observation and reciprocal feedback from the environment. Actions supported their knowledge while discovering what worked and what did not, forming a continuous cycle that generates information and knowledge. Each step created a "different" situation. The "sensed" situation, or the situation they used for management, will not exist for later review. Only the "monitored" situation will; that is the situation they could describe to others, use for documentation, and learn. The two situations are not identical. The mountain drives reality. Climbers change models with each step and each storm. Scientists developed models for use on the mountain. Prediction with inaccurate models and communication with imperfect descriptions will kill (18).

Like the climber's goal to gain altitude, the neonatologist's goal is to gain life. High altitude climbers must explore different routes to reach the summit, and even known routes may not be available depending on snow and weather. This process is valid for the care of a specific baby, for resuscitations, and discipline. Unlike other specialties, neonatology does not have an endpoint; gaining life means entering an altitude never before attained, which becomes the basis for the next increase. Climbing does not have an endpoint; each step is a different step, and every mountain is a different mountain.

\section{Engagement Advances Climbing:}

The liminal space is not only a physical space; it is a social space 
(21). An individual with high altitude climbing and medicine or physiology expertise can fall into a social liminal space. Griffith Pugh and George Finch were mountaineers and scientists. Not fully respected by high altitude climbers for their science and not accepted into the social club of gentlemen who also climb.

\section{"Like the climber's goal to gain altitude, the neonatologist's goal is to gain life. High altitude climbers must explore different routes to reach the summit, and even known routes may not be available depending on snow and weather. This process is valid for the care of a specific baby, for resuscitations, and discipline."}

\section{George Finch}

The Making of a Mountaineer by George Finch (55) was a mountaineering classic when published in 1924, inspiring generations of mountaineers (17). Finch had advocated for the use of oxygen, including at rest after his experience spending two unplanned nights at 25,500 feet (56). Hunt recognized his advocacy for oxygen heavily influenced its use on the successful 1953 Everest expedition(11). The equipment used was similar to that developed by Finch for the 1922 expedition (17). He believed that above 23,000 feet, the physical deterioration from poor sleep and appetite outweighed the benefit of acclimatization (56). He also was a strong advocate for better food, including pre-packed rations (56). As a scientist with engineering skills, he participated in equipment design and advised the Everest Committee on oxygen (17). John Hunt lauded Finch for showing how the physiological problems might be solved (17).

Despite setting an altitude record of 27,320 feet on the 1922 Everest expedition, Finch was excluded from the 1924 expedition (56). Until he set that record, he had been denied membership to the Alpine Club (56). He had been denied the opportunity to participate in several Mount Everest expeditions because of his personality (17).

An elitist system dominated British alpine climbing. Finch did not fit in because of his reputation for being outspoken and an unconventional Australian. He had made guideless ascents, which many members of the Alpine Club opposed. Odd by today's standards, but "scientist" was not a respectable occupation for a gentleman (17). Personal interactions and social standards excluded an individual who could engage in high altitude climbing with science and ensure the accuracy of the high altitude climbing models.

\section{Gifford Pugh}

Gifford Pugh served an internship at Lambeth Hospital, London. He competed in downhill, slalom, and cross-country ski races during his university studies, being selected for the 1936 Olympic cross-country team. An injury prevented his participation. He had experience climbing regularly in Europe. During WWII, he joined the Ski and Mountaineering School at the Cedars of Lebanon, training mountain troops and Special Operations Executive (SOE) in survival techniques. In Lebanon, he studied research on fatigue and conducted his studies evaluating soldiers for mountain warfare. This included developing soldiers' physical capacity, the equipment they used, and their diet $(56,57)$.

Michael Ward, a physician and mountain climber, had conceived of climbing Everest from the south and became involved with the Everest expeditions. His pursuit of physiology as the primary impediment led him to Gifford Pugh (57). Their discussions developed the need for high flow rates of supplementary oxygen, a large daily fluid intake, and adequate protective clothing and boots $(11,56,57)$.

Pugh's plan included oxygen, including descent and sleep, for climbers and Sherpa above 23,000 feet. Acclimatization for four weeks. Water at 3-4 liters per day. A European diet for the climber with special meals for climbers going to high altitude. Better hygiene, including food hygiene. They would not sleep in local houses. [The heat is considered to be contained in the smoke; therefore, they do not build chimneys in their homes. DvS] Better clothing used a thermal insulation system ("Clo values"), sleeping bags that pull over the head, and RAF masks adapted for climbing (56).

Pugh brought Everest the expertise of the high altitude climber and expertise in science, marrying the two through synthesis and similar inductive processes. His was not a hybrid approach or a back-and-forth activity. Pugh engaged the discontinuity between contextual practice and decontextualized theory (19), the separation between continuous perceptions and static, discrete concepts (20), and the separated concepts of sensemaking (58) and enactment $(59,60)$.

\section{Hidden voices and the dominant account}

Once a dominant account develops, voices become hidden, and knowledge is lost. For example, a dominant account developed for the 1996 Mount Everest disaster (6) about teamwork, decisionmaking, how to offset individuals' natural shortcomings, and selfdiscipline among the topics, making the story amenable to business leadership. With the dominant account, we lose the effect of the liminal experience (21) and the liminal space (5). The dominant account reduces problems within the liminal space to science versus practice, which creates inaccurate models - models that can kill (18). This is not from history and not from an event too large for us. After the action, interviews of fire and EMS responders to a terrorist shooting initially reflected the dominant account. Because we ensured each interview team had one member with extensive experience in live-or-die situations, the interviewee would rapidly begin an accurate description of their experience. Information had changed (61). We chose the climber's hidden voices in extreme environments - high altitude, cold, isolated - to investigate the 30year failure to climb Mount Everest successfully. Then the abrupt success.

First-person accounts of the 1996 Everest disaster have created a large number of "lessons learned" articles for business leadership. This body of literature, each article was written by a single individual involved but without perspectives from other participants, has become the dominant account of the disaster. Michael Elmes and Bob Frame (6) interviewed those with hidden voices, other climbers and Sherpa porters. 
The dominant account becomes a mistranslation of a liminal event, reduced and simplified to fit a normative view framed from a spectator's fixed point. Context and meaning, critical for engagement, is lost. The dominant group sets the discourse, defines categories and classifications, sets limits of what can be spoken about and what cannot, and who can speak with legitimacy. The dominant account is the privilege of being listened to (6).

The dominant account excludes contextual elements such as physiological factors, the weather, and the business nature of adventure climbing. Consider the strenuous exercise, minimal sleep, poor nutrition, and dehydration in the participants, constraining rational and effective decision-making and team formation. Published discussions and 'lessons learned' do not reflect the physiological and mental demands in the high altitude environment described and quoted in this article. The armchair climber and disaster expert can think now and give sage advice. The dominant account too readily becomes disaster voyeurism.

The Sherpas are hidden voices in the 1996 disaster, as they are in the Everest saga (57). A bottleneck occurred halfway up the mountain attributed to the two lead Sherpas' failure, referencing one as a 'showboat' and a 'gold- brick.' Some of this comes from clients' perceptions, sojourners having little contact with a Sherpa and ignorant of Sherpa culture. The dominant account became one of the Sherpas lacking discipline and succumbing to self-centered interests.

\section{"Success in this environment comes from the hidden voices, the neonatologist, physician, nurse, respiratory care, dietitian, ward clerk, family, and more. Build the expertise to which you will later defer. Nevertheless, listen to the hidden voices."}

\section{Conclusion:}

The successful climb of Mount Everest in 1953 followed the incorporation of several individuals, Gifford Pugh and Michael Ward, with the necessary expertise to engage the science and the environment. Engagement builds on perception and inquiry, which generates Shannon information (Shannon information is the information generated when uncertainty is converted to certainty.) Knowledge from both observations and "information of experience" must be continuously proven accurate by continued engagement and inductive processes. Pragmatism, always moving ahead by monitoring for consequences of our actions, is a necessity for austere or hazardous situations. Resolution of our experience produces the meaning of what we accomplished.

Whether a liminal space, high altitudes, or the ecology of fear, we enter with engagement and inquiry to generate information. Through inductive processes, we penetrate the unknown, using pragmatism for direction and guidance. This dynamic, which reduces complexity using reciprocal feedback, is shared between mountain climbers entering high altitudes to gain altitude and neonatologists engaging hazardous physiology to gain life. This richness is not found in the dominant account. It lies with the hidden voices.

Success in this environment comes from the hidden voices, the neonatologist, physician, nurse, respiratory care, dietitian, ward clerk, family, and more. Build the expertise to which you will later defer. Nevertheless, listen to the hidden voices.

\section{References:}

1. Shipton E. The Mount Everest reconnaissance expedition 1951. Hachette, UK: Hodder and Stoughton Limited; 1952.

2. Pugh LGCE. Physiological and medical aspects of the Himalayan Scientific and Mountaineering Expedition. British medical journal 1962;2(5305):621-7.

3. Milledge JS. The "Silver Hut" expedition-A commentary 40 years later Wilderness \& environmental medicine. 2002;13(1):55-6.

4. West JB. American medical research expedition to Everest. High Altitude Medicine \& Biology. 2010;11(2):103-10.

5. Tempest S, Starkey K, Ennew C. In the Death Zone: A study of limits in the 1996 Mount Everest disaster. Human Relations. 2007;60(7):1039-64.

6. Elmes $M$, Frame B. Into hot air: A critical perspective on Everest. Human Relations 2008;61(2):213-41.

7. Bruce CG. The Assault on Mount Everest, 1922 London, UK: E. Arnold \& Company; 1923.

8. Tilman HW. Everest 1938: Whether these mountains are climbed or not, smaller expeditions are a step in the right direction. Cambridge, UK: Cambridge University Press; 1948.

9. Ullman JR. High Conquest: The story of mountaineering. New York, NY: J. B. Lippincott; 1941.

10. Shipton EE. Upon that Mountain. Hachette, UK: Hodder \& Stoughton; 1947.

11. Hunt J. The Conquest of Everest. New York, NY: E. P. Dutton \& Co; 1954.

12. Norton EF. The Fight for Everest 1924: Mallory, Irvine and the Quest for Everest. Sheffield, South Yorkshire: Vertebrate Publishing; 2015.

13. Hillary E. The Summit. In: Hunt J, editor. The Conquest of Everest. New York, NY: E. P. Dutton and Company; 1954. p. 197-209.

14. Shipton E. The Expedition to Cho Oyu. The Geographical Journal 1953;119(2):129-37.

15. Howard-Bury CK. Mount Everest: The reconnaissance, 1921. London, UK: Edward Arnold \& Co. ; 1922.

16. Douglas CG, Haldane JS, Yandell Henderson, Schneider EC. VI. Physiological observations made on Pike's Peak, Colorado, with special reference to adaptation to low barometric pressures. Philosophical Transactions of the Royal Society of London Series B, Containing Papers of a Biological Character. 1913;203(294-392):185-318.

17. West JB. George I. Finch and his pioneering use of oxygen for climbing at extreme altitudes. Journal of Applied Physiology 2003;94(5):1702-13.

18. Heggie V. Experimental physiology, Everest and oxygen: from the ghastly kitchens to the gasping lung. The British Journal for the History of Science. 2013;46(1):123-47. doi: $10.1017 /$ s0007087412000775. 
19. Zundel $M$, Kokkalis $P$. Theorizing as engaged practice. Organization Studies 2010;31(9-10):1209-27.

20. Weick KE. Organizing for Transient Reliability: The Production of Dynamic Non-Events. Journal of Contingencies and Crisis Management. 2011;19(1):21-7. doi: 10.1111/j.14685973.2010.00627.x.

21. Morris DJ. The Evil Hours: A biography of post-traumatic stress disorder. Boston, MA: Houghton Mifflin Harcourt; 2015.

22. van Stralen D, Mercer TA. Pandemic COVID-19, the HighReliability Organization (HRO), and the Ecology of Fear. Neonatology Today. 2020;15(12):129-38.

23. Mattson MP. Superior pattern processing is the essence of the evolved human brain. Frontiers in neuroscience 2014;8(265):1-17.

24. van Stralen D. Pragmatic HRO during Pandemic Covid-19. Neonatology Today. 2020;15(4):3-9.

25. Öhman A, Lundqvist $D$, Esteves $F$. The face in the crowd revisited: a threat advantage with schematic stimuli Journal of personality and social psychology. 2001;80(3):381-96.

26. van Stralen D, Mercer TA. During Pandemic COVID-19, the High-Reliability Organizations (HRO) Identifies Maladaptive stress Behaviors: The Stress-Fear-Threat Cascade. Neonatology Today. 2020;15(11):113-23.

27. Rogers LJ. Lateralization in Vertebrates: Its Early Evolution, General Pattern, and Development. Advances in the Study of Behavior 2002;31:107-61.

28. Cozolino L. The Neuroscience of Human Relationships: Attachment and the Developing Social Brain. New York, NY: W. W. Norton; 2006.

29. van Stralen D, Mercer TA. Pragmatic High-Reliability Organizations (HRO) Modulate the Functions of Stress and Fear Behaviors during Pandemic COVID-19: The Stress-FearThreat Cascade. Neonatology Today. 2020;15(10):126-34.

30. van Stralen D, McKay SD, Mercer TA. Pragmatic Leadership Practices in Dangerous Contexts: High-Reliability Organizing (HRO) for Pandemic COVID-19. Neonatology Today. 2020;15(8):109-17.

31. van Stralen D, McKay SD, Mercer TA. Flight Decks and Isolettes: High-Reliability Organizing (HRO) as Pragmatic Leadership Principles during Pandemic COVID-19. Neonatology Today. 2020;15(7):113-22.

32. Pólya G. Induction and analogy in mathematics. Princeton, NJ: Princeton University Press; 1954.

33. Hickman LA. Pragmatism as post-postmodernism: Lessons from John Dewey. New York, NY: Fordham University Press; 2007.

34. Star SL. Living grounded theory: Cognitive and emotional forms of pragmatism. In: Bryant $A$, Charmaz $K$, editors. The Sage handbook of grounded theory. Los Angeles, CA: Sage Publications; 2007. p. 75-94.

35. Leddy T. Dewey's Aesthetics. In: Zalta EN, editor. The Stanford Encyclopedia of Philosophy Stanford University Press; 2020.

36. Legg C, Hookway C. Pragmatism. In: Zalta EN, editor. The Stanford Encyclopedia of Philosophy: Stanford University Press; 2020.

37. Park CL. Making Sense of the Meaning Literature: An Integrative Review of Meaning Making and Its Effects on Adjustment to Stressful Life Events. Psychological Bulletin. 2010;136(2):257-301.
38. Alexander TM. The Human Eros: Eco-ontology and the Aesthetics of Existence. New York: NY: Fordham University Press; 2013.

39. Kolditz TA, Brazil DM. Authentic leadership in in extremis settings: A concept for extraordinary leaders in exceptional situations. In: Gardner WL, Avolio BJ, Walumbwa FO, editors. Authentic leadership theory and practice: Origins, effects and development. 3. Amsterdam, Netherlands: Elsevier; 2005. p. 345-56.

40. Bonanno GA, Burton CL. Regulatory Flexibility: An Individual Differences Perspective on Coping and Emotion Regulation. Perspectives on Psychological Science. 2013;8(6):591-612.

41. Fesmire S. John Dewey and moral imagination: Pragmatism in ethics. Bloomington, IN: Indiana University Press; 2003.

42. van Stralen $D$, Rogers $M$, Perkin RM, Fea S. Retrograde intubation training using a mannequin. The American journal of emergency medicine. 1995;13(1):50-2.

43. van Stralen $D$, Perkin RM. Retrograde intubation difficulty in an 18-year-old muscular dystrophy patient. American Journal of Emergency Medicine. 1995;13(1):100-1.

44. Cox P, L. R. Wager, Norton EF, Brocklebank TA, Smythe FS, Bruce G, et al. The Mount Everest Expedition, 1933: Discussion. The Geographical Journal. 1934;83(1):9-17.

45. Firth $P G$, Zheng $\mathrm{H}$, Windsor JS, Sutherland Al, Imray $\mathrm{CH}$, Moore GWK, et al. Mortality on Mount Everest, 1921-2006. descriptive study. BMJ. 2008;337(a2654):1430-3.

46. Pavy-Le Traon A, Heer M, Narici MV, Rittweger J, Vernikos J. From space to Earth: advances in human physiology from 20 years of bed rest studies (1986-2006. European Journal of Applied Physiology. 2007;101(2):143-94.

47. Haldane JS, Kellas AM, Kennaway EL. Experiments on acclimatisation to reduced atmospheric pressure. The Journal of physiology. 1919;53(3-4):181-206.

48. Ruttledge $H$. The Mount Everest Expedition, 1933. The Geographical Journal. 1934;83(1):1-9.

49. Bloom BS, Engelhart MD, Furst EJ, Hill WH, Krathwohl DR. Taxonomy of Educational Objectives: The Classification of Educational Goals. Handbook I: Cognitive Domain. 7th ed. New York, NY: David McKay Company; 19561972.

50. Krathwohl DR, Bloom BS, Masia B. Taxonomy of Educational Objectives Handbook II: Affective domain. New York, NY: David McKay Company; 1964.

51. Haldane JS. Organism and Environment as Illustrated by the Physiology of Breathing. New Haven, CT: Yale University Press; 1917.

52. Pugh LGCE. Man at high altitude. Journal of the Royal College of Physicians of London. 1969;3(4):385-97.

53. Greene R. Observations on the composition of alveolar air on Everest, 1933. The Journal of physiology. 1933;82(4):481-5.

54. Watt JWH, Silva P. Respiratory alkalosis and associated electrolytes in long-term ventilator dependent persons with tetraplegia. Spinal cord 2001;39(11):557-63.

55. Finch GI. The Making of a Mountaineer. London, UK: Arrowsmith; 1924.

56. Tuckey HP. Everest-The First Ascent: The untold story of Griffith Pugh, the man who made it possible. Guilford, CT: Lyons Press; 2013.

57. Ward MP, Milledge JS. Griffith Pugh, pioneer Everest physi- 
ologist. High Altitude Medicine \& Biology. 2002;3(1):77-87.

58. Weick KE, Sutcliffe KM, Obstfeld $D$. Organizing and the Process of Sensemaking. Organization Science. 2005;16(4):409-21. doi: 10.1287/orsc. 1050.0133.

59. Weick KE. Enacted sensemaking in crisis situations. Journal of Management Studies. 1988;25(4):305-17.

60. Weick KE. Sensemaking in Organizations Thousand Oaks, California: Sage Publishing; 1995.

61. van Stralen D, McKay SD, Williams GT, Mercer TA. Tactical Improvisation: After-Action/ Comprehensive Analysis of the Active Shooter Incident Response by the San Bernardino City Fire Department December 2, 2015. San Bernardino, CA: 2017.

Disclosure: The authors have no disclosures.

NT
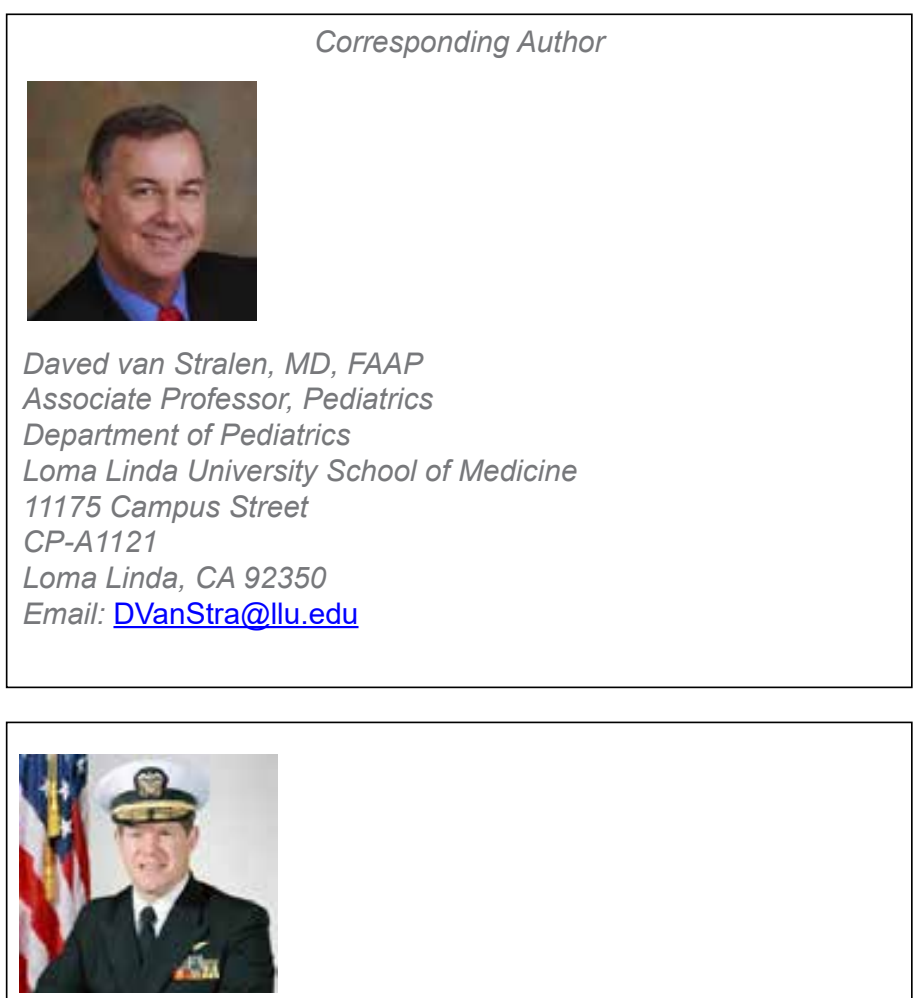

Thomas A. Mercer

Rear Admiral

United States Navy (Retired)

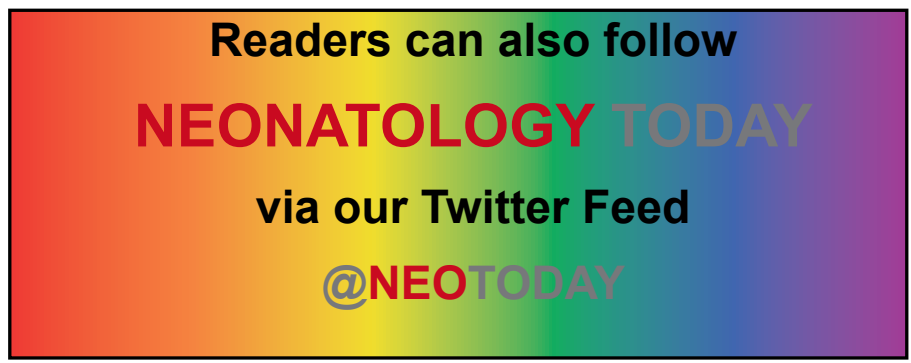

\section{Acknowledgments}

Raymond Novaco, Professor, Psychology and Social Behavior, School of Social Ecology, University of California, Irvine, California

Karl Weick- review and editing, Rensis Likert Distinguished University Professor of Organizational Behavior and Psychology, Emeritus, University of Michigan

William J. Corr, formerly with the Los Angeles City Fire Department, now deceased

Errol van Stralen, Ancora Education

Sean D. McKay, Element Rescue, LLC

William Gambino, CIV, DoD

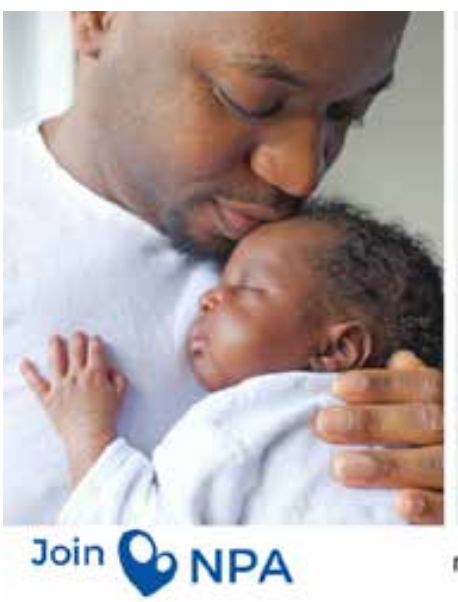

Did you know that

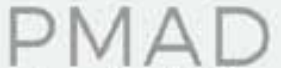

related suicides account for

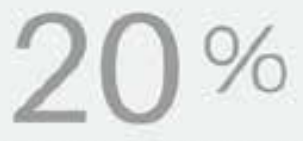

of Postpartum Maternal Deaths?

nationalperinatal.org/mental_health

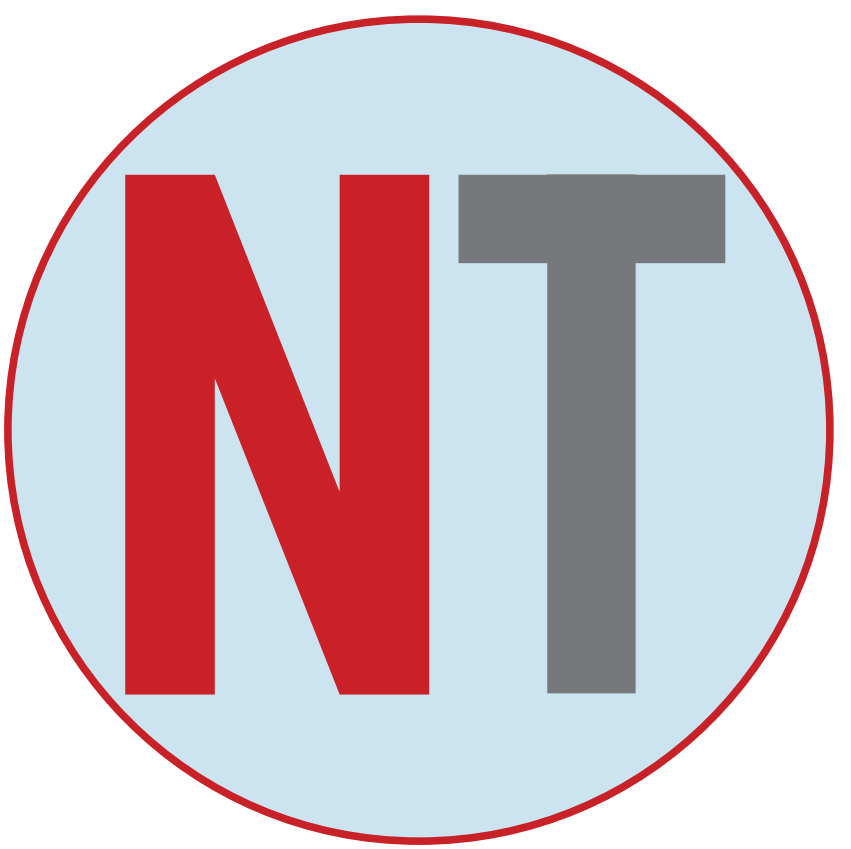

